\title{
Modos contemporâneos de aprendizado e construção do conhecimento: reflexões sobre o ensino de Teoria da Computação para Sistemas de Informação
}

\author{
Isabel Cafezeiro ${ }^{1,2}$, Leonardo Cruz da Costa ${ }^{1,3}$, Ricardo Kubrusly ${ }^{2}$ \\ ${ }^{1}$ Instituto de Computação - Universidade Federal Fluminense (UFF) \\ Niterói - RJ - Brasil \\ ${ }^{2}$ Programa de Pós-Graduação em História das Ciências e das Técnicas e Epistemologia \\ (UFRJ) Rio de Janeiro - RJ - Brasil \\ ${ }^{3}$ Programa de Pós-Graduação em Ciências da Informação (UFF) \\ Niterói - RJ - Brasil \\ \{isabel, leo\}@ic.uff.br, risk@hcte.ufrj.br
}

\begin{abstract}
This article describes the experience of designing and implementing a discipline in the under graduation course in Information Systems that seeks to address the contents of the Theory of Computation, a topic that has been, over the years, deprecated in Computer Science courses and that is not part the usual curricula in Information Systems. We argue that a proposal based on interdisciplinarity through sociotechnical approach can reframe these contents bringing out a great contribution to the understanding of the current configuration of computer systems through its historical process of construction.
\end{abstract}

Resumo. Este artigo descreve a experiência de concepção e implantação de uma disciplina em curso de Sistemas de Informação que procura abordar o conteúdo de Teoria da Computação, um tema que vem sendo ao longo dos anos preterido nos cursos de Ciências da Computação e que não faz parte dos currículos usuais em Sistemas de Informação. Argumentamos que uma proposta ambientada na interdisciplinaridade através da abordagem sociotécnica pode reposicionar estes conteúdos colocando em evidência uma grande contribuição na compreensão da configuração atual dos sistemas computacionais através do seu processo histórico de construção.

\section{As duas culturas}

Nossas análises têm por base a observação dos cinco primeiros anos de operação do curso de Sistemas de Informação da Universidade Federal Fluminense (UFF), na cidade de Niterói, RJ. Arriscamos um diagnóstico ao problema do alto grau de retenção de estudantes nos primeiros três períodos do curso. Trata-se justamente do momento em que se concentram as disciplinas de base matemática, como cálculo, lógica e matemática discreta, que apresentam um conteúdo não familiar tanto para o estudante recém-saído do ensino médio quanto para os que já possuem alguma experiência no mercado de trabalho em Sistemas de Informação e retornam à universidade em busca da 
titulação. Completam o quadro de retenção as disciplinas iniciais de programação ${ }^{1}$, também ministradas nos primeiros períodos.

A retenção não é uma característica exclusiva dos cursos de Sistemas de Informação. Ela também se faz presente nos cursos de Ciências da Computação, referente a este mesmo conjunto de disciplinas. De modo geral em computação, retenção, dificuldade de aprendizagem e evasão vem demandando atenção nos fóruns de discussão de currículos e metodologias de ensino ${ }^{2}$, e surpreende que este problema não tenha ainda encontrado solução satisfatória em cursos de longa tradição como os de Ciência da Computação (o curso de graduação em Ciências da Computação da UFF, em Niterói, foi implantado em 1986, mas os primeiros do Brasil datam de 1969). Porém é possível que os cursos de Sistemas de Informação, por fundamentarem-se em uma abordagem diferente e recente quando comparada ao tradicional enfoque em Ciências da Computação, sejam capazes de atrair atenção para uma nova dinâmica de compreensão do conhecimento, algo que pode ser elaborado de maneira a sugerir transformações e metodologias inovadoras no ensino tanto em Sistemas de Informação quanto nas Ciências da Computação. Trata-se da abordagem sociotécnica.

Desde os primeiros contatos com as apresentações dos cursos de Sistemas de Informação, o aluno percebe que se trata de um campo de conhecimento não completamente incluso na área de Ciências da Computação. As páginas de apresentação dos cursos costumam indicar uma forte interdisciplinaridade, em que a computação é situada como atividade meio, capaz de capacitar o profissional para a utilização instrumental da tecnologia na solução criativa de problemas diversos. É uma abordagem que encontrou suporte nos documentos referenciais da área, como o currículo de referência da Sociedade Brasileira de Computação (SBC, 1999). Essa multiplicidade de campos de conhecimentos manifestou-se na grade curricular do Curso de Sistemas de Informação da UFF pela colaboração com diversos departamentos (direito, sociologia, psicologia, administração, ciências da informação) através do oferecimento de disciplinas em turmas mistas (não exclusivas a estudantes de Sistemas de Informação), o que veio a fortalecer o diálogo dos estudantes com as demais áreas. Fora das salas de aula, o curso contou com o apoio de um Núcleo Docente Estruturante, e com o Colegiado de Curso, que, atentos ao caráter híbrido requerido na formação do profissional de Sistemas de Informação, contribuíram para oferecer com sucesso a diversificação do corpo de conhecimentos presente na grade curricular.

O que não se verificou, entretanto, foi a efetivação da abordagem sociotécnica no interior de cada disciplina, e principalmente daquelas disciplinas consideradas "exatas", como as matemáticas. O estudante se deparou com uma perceptível fronteira:

\footnotetext{
${ }^{1}$ No caso da programação de computadores, precisamos notar que o mecanismo de raciocínio que esta disciplina exige difere da práxis do ensino médio, onde os conteúdos considerados exatos são apresentados em uma abordagem predominantemente teoremática (isto é, que não deixa aparentes processo e motivação de construção das formulas, focando-se o modo de aplicação, e, quando muito, justificativas dedutivas). Diferentemente, a atividade de programação exige um pensamento algorítmico, centrado no "como fazer", raciocínio aderente ao problema. Sobre a diferença entre as abordagens teoremática e problemática, ver Deleuze \& Guatarri (1997, p. 26).

${ }^{2}$ Para um exemplo recente, remetemos ao Curso de Qualidade da Sociedade Brasileira da Computação (CQ, 2015), cujo tema foi "Evasão e estratégias para permanência estudantil"

(http://csbc2015.cin.ufpe.br/eventos_descricao/8). Percebemos também que o tema é recorrente nas diversas edições do WEI. No ano de 2015, por exemplo, podemos ver Souza, Morais, \& Junior (2015).
} 
as disciplinas ministradas pelos departamentos de computação e matemáticas são apresentadas como "técnicas" (ou "exatas"). O aprendizado é centrado em mecanismos abstratos ou metodologias validadas no cenário acadêmico mundial e as avaliações focalizam a aplicação destes mecanismos. As outras disciplinas, principalmente as ministradas nos departamentos das áreas humanas são apresentadas como disciplinas "humanísticas", "não-técnicas". Neste caso, o debate e a expressão oral e escrita são incentivados, e as avaliações não seguem necessariamente o formato das provas tradicionais e a abordagem demanda um posicionamento crítico pessoal que se afasta de um caráter supostamente neutro, usual no ensino das técnicas. Sem que se efetive o diálogo entre estas abordagens, modo de apresentação, conteúdos, avaliações, tudo se altera quando se passa de um universo para o outro. É uma diferença que acompanha a configuração dos saberes modernos, e que na UFF se faz visível também espacialmente, na separação dos campi universitários (as disciplinas humanísticas são oferecidas no Campus do Gragoatá, onde se concentram os departamentos e cursos correspondentes. Por outro lado, o Instituto de Computação se localiza no Campus da Praia Vermelha, e lá são ministradas as disciplinas da matemática e da computação). Latour (2014, tradução nossa) observou:

[P]arece que estamos sofrendo de uma divisão do trabalho intelectual: se você aprendeu história, ciências sociais, literatura, direito, arte ou qualquer ramo do que é chamado de "humanidades", tenho certeza que você aprendeu um monte de coisas, mas não necessariamente sobre como a tecnologia e a ciência têm interferido em todos esses vários campos; por outro lado, se você assistiu aulas ou teve formação em engenharia, informática, ciências naturais ou negócios aplicados, não tenho a certeza que você vai ter aprendido algo sobre quando, onde e por quem esses elementos de conhecimento foram produzidos e que eles relações entretêm com a história, literatura, arte, política ou ciências sociais. (...) Qualquer que seja o campo de onde você vem, há chances de que você tenha percebido de que existe uma divisão entre aqueles que vêm "das letras" e aqueles que vêm "das ciências". E não apenas uma divisão, mas muitas vezes, infelizmente, alguma forma de condescendência, mesmo de rancor contra os do outro lado: você poderia ter sido tratado como um "nerd analfabeto" por algum estudioso literário brilhante que, por sua vez, poderia ter sido tratado como um "idiota romântico" por alguns colegas do sério departamento de matemática.

Diante desse quadro de cisão entre os conhecimentos, recusamos qualquer diagnóstico referente à retenção, evasão e dificuldades de aprendizagem que se situe na falta de preparo dos estudantes de Sistemas de Informação, e arriscamos dizer que o baixo desempenho nas disciplinas das ditas "ciências exatas" nasce no conflito entre a expectativa por um conhecimento híbrido e problematizador e o defrontamento com um conhecimento que se pretende puramente técnico. Este conflito é desmotivador, uma vez que não conduz à compreensão da utilidade destes conhecimentos na profissão. Traz para a reflexão o contraste com o alto desempenho nas ditas "humanísticas", um fato que, ignorando-se a familiaridade destes conteúdos a estes estudantes desde o ensino médio, ainda desencadeia o argumento de que as chamadas "humanísticas" são "mais fáceis" do que as ditas "exatas". A este impasse, referindo-se especificamente à Engenharia de Software, Cukierman et al., em 2007 já haviam proposto um caminho:

A saída para os impasses criados pela separação entre o técnico e o social consiste em mudar o ângulo de aproximação e, assim, percebê-los por um novo enquadramento. Resumindo brevemente, um enquadramento em que o técnico e o social constituem um movimento de "comodificação", somente percebido por uma abordagem concomitantemente social e técnica, por um olhar sociotécnico. Um olhar que busca apreender a ES sem fragmentá-la em "fatores ou aspectos técnicos" de um lado, e "fatores ou aspectos nãotécnicos" de outro, sem fatorá-la em quaisquer outras dualidades ("fatores técnicos" versus "fatores humanos, organizacionais, éticos, 
políticos, sociais, etc.") que terminem por desfigurar o "pano sem costura" que imbrica na ES o técnico e o social em um mesmo e indivisível tecido.

\section{Teoria da Computação e os currículos de Sistemas de Informação}

Se por um lado a saída apontada por Cukierman et al. encontra acolhimento em áreas como a Engenharia de Software, Interação Humano-Computador, Jogos, e outras especialidades que, de uma forma ou de outra, admitem algum diálogo com a sociedade, o mesmo não se verifica com a área da Teoria da Computação. Aqui, nos referimos precisamente aos conhecimentos relacionadas ao estudo da Computabilidade.

Muitas questões abordadas no campo da Computabilidade se estabeleceram antes da construção dos primeiros computadores, em um ambiente de busca pela compreensão da capacidade de expressão formal (sistemas formais). Naquele momento, início do século XX, percebiam-se certas idiossincrasias, como os paradoxos e enunciados não provados, que não eram bem-vindas numa ciência que buscava controle, exatidão e objetividade. Mas, em consonância com a concepção da ciência moderna de uma matemática completa e totalizante, buscavam-se no seio da própria matemática, explicações para essas esquisitices, dando margem aos programas de fundamentação da matemática do início do século XX (Cafezeiro et al, 2010). Resultados concebidos no contexto da afirmação da matemática enquanto disciplina autônoma migraram para a computação como fundamentação para o campo incipiente. Dali para a década de 1960, já com cerca de 15 anos de operação dos computadores, outros personagens, os fundadores da computação, reconheceram no estudo de sistemas formais e suas propriedades o coração da computação e a justificativa para a institucionalização do campo. Daí se compreende uma certa resistência para a abordagem híbrida: herança da tradição matemática como um campo purificado, que não se contamina com os demais, fortalecimento do caráter científico do novo campo a partir da aderência a um campo já estabelecido. Embora alguns cientistas, como Alan Perlis, insistissem na interação com saberes relacionados à gestão e à informação, outros pioneiros do campo da computação, como Edsger Djkstra, Tony Hoare, Nicklaus Wirth, apostaram no caráter "exato" e se opuseram à institucionalização do campo em co-construção com outros saberes "não exatos".

Argumentos em favor das abordagens formais podem ser lidos nos relatórios das famosas conferências da OTAN (Organização Militar do Atlântico Norte) de 1968 e 1969 (NATO 1969,1970), onde, sob o pretexto de discutir a "crise do software", terminou-se por delimitar os contornos do que se passou a chamar de "Ciência da Computação". O trecho a seguir mostra o quão frágil era, naquele momento a compreensão do campo que vinha então se configurando (NATO,1970, tradução nossa,p.49):

Strachey: (...). Acho que devemos nos perguntar seriamente a seguinte questão: é a computação uma ciência? (...) Até termos um corpo suficiente de tópicos que sejam importantes, relevantes e bem desenvolvidos, não podemos chamar o assunto de "ciência".

Woodger: Eu me pergunto com o se parece que um princípio básico em informática, se eu me deparasse com um. Sério! Em que termos ele poderia ser expresso? Não é bom usar termos inexplicáveis como "língua" ou "compilador"; temos muito poucos termos claros em que para expressar qualquer princípio fundamental da ciência da computação. Será que algum professor aqui pode me dizer um único princípio básico? 
Grande parte das discussões girava em torno de um impasse entre "teoria" e "prática". Os defensores da "teoria" encontravam nos métodos matemáticos a garantia de um campo bem fundamentado e uma atividade de programação livre de erros. Aqui Hoare e Dijkstra, em divergência com Perlis, ironizam os testes informais em programas e argumentam em favor das provas formais (NATO, 1970,p.16):

Hoare: Pode-se, muito facilmente, construir provas convincentes da futilidade de testes exaustivos em um programa e até mesmo de testes por amostragem. (...) Teste dos casos base poderiam, por vezes, serem automatizados. Atualmente, isto é basicamente teoria (...) Esta área de trabalho teórico parece mostrar uma possibilidade de resultados práticos, embora provar correção seja um processo trabalhoso e caro. Talvez não seja um luxo para certas áreas cruciais de um programa.

Perlis: Grande parte da complexidade do programa é espúria e uma série de casos de teste devidamente estudados esgota o problema dos testes. O problema consiste em isolar casos de teste adequados, e não provar o algoritmo, pois isto [a correção] se segue após a escolha dos casos de teste adequados.

Dijkstra: Teste mostra a presença, não a ausência de bugs.

Possivelmente em função do forte apelo dos pioneiros que argumentavam em favor de métodos formais, questões relacionadas à decidibilidade ganharam importância nos currículos da computação, no sentido da compreensão das capacidades e limitações das abordagens formais. No Brasil, a maioria dos cursos em computação que começaram a surgir na década de 1970 (as exceções são Ciências da Computação da UNICAMP e Processamento de Dados da UFBA que iniciaram em 1969) contava com disciplinas referentes tanto à parte de linguagens formais e autômatos, onde aparecem questões de decidibilidade, quanto aos conteúdos relacionados à enumerabilidade, Tese de Church, Máquina Universal. Mas, da década de 1970 aos dias de hoje, estes conhecimentos vêm perdendo espaço nos currículos da computação, e são praticamente inexistentes nos cursos de Sistemas de Informação, um campo que toma como periférica a importância destes saberes na formação profissional.

Ao mesmo tempo que verificamos que a abordagem usual da computabilidade é extremamente matematizada, centrada na apresentação de resultados e provas formais, e portanto, se afasta do enfoque sociotécnico buscado nos cursos de Sistemas de Informação, vemos também que a ausência destes assuntos causa um lapso nesta formação no que tange a compreensão das possibilidades de sistemas computacionais, a configuração atual de sistemas computacionais e suas perspectivas futuras e também a compreensão desenvolvimento da computação e do próprio computador. Acrescentamos ainda que a presença ubíqua da computação em nossas vidas vem demandando uma compreensão em termos teóricos (no suporte matemático), filosóficos e sociológicos que capacite os profissionais da computação a lidar com a nova dinâmica social fortemente amparada nas tecnologias. Por isso, convém refletir sobre a concepção de uma maneira sociotécnica de trabalhar estes conhecimentos. Longe de pretender desenvolver uma abordagem "suavizada" da abordagem formal, o que está aqui em questão é o resgate destes conteúdos devido à sua importância nas formações em computação. A estratégia é desfazer a cisão entre os resultados matemáticos e as questões do mundo que lhes motivaram, buscar maneiras de apresentar conteúdos formais das disciplinas de Computabilidade inseridos na conjuntura que suscitou a sua formulação para que sejam compreendidos mais amplamente. Por exemplo: os números transfinitos de Cantor, suas propostas de compreensão do infinito, e suas percepções 
sobre cardinalidades nos parecem ainda hoje esquisitos porque fugiam do que era considerado "intuitivo". No entanto, as formulações de Cantor não buscavam refletir diretamente o que a grande maioria considerava "intuitivo", mas eram inspiradas nos dilemas religiosos de caráter muito intimista que Cantor vivia (Junior, 2006). Portanto, sob a luz destas inquietações as construções matemáticas de Cantor se deixam explicar mais claramente. Da mesma forma, se percebermos os movimentos artísticos que se desenrolavam na Europa dos anos 1930, que tem uma das primeiras expressões na revolta do dramaturgo Antonin Artaud com relação à compreensão da potência da representação (Cafezeiro, Gadelha \& Chaitin, 2016), podemos verificar que as indagações formuladas pelos matemáticos com relação à representação matemática acompanhavam uma tendência daquela sociedade naquele momento. A Europa, em consequência da guerra recente, do autoritarismo dos governos e na iminência de uma nova guerra vivia um momento de crise nas representações, incluindo-se aí as representações políticas. Isto, embora seja claro em estudos sociológicos, artísticos e filosóficos, para os matemáticos é um ponto que ainda necessita ser debatido. Alguns cientistas matemáticos preferem considerar os resultados matemáticos como questões livres de qualquer influência do mundo em que viviam os matemáticos. Seriam questões limitadas ao escopo da própria disciplina: "Muitas referências ao teorema da incompletude fora do campo da lógica formal são obviamente absurdas e parecem basear-se em mal-entendidos graves ou algum processo de livre associação" (Franzen, 2005). Por fim, cabe mencionar a própria construção do computador, cuja compreensão não se dissocia da conjuntura da segunda guerra (Dyson, 2012). Quando acompanhados das circunstâncias complexas em que foram concebidos, aquilo que vem sendo usualmente apresentado como sendo "essencialmente matemático" ou "essencialmente técnico" passa a mostrar um caráter inevitavelmente interdisciplinar. Por esse caminho, abre-se espaço a novas traduções, interpretações e conexões com questões da contemporaneidade. Segue-se um exemplo.

Em meados do ano de 2013 começaram a aparecer na mídia carioca diversas notícias referentes a um novo campo da computação denominado "Computação Humana" (Setti, 2013). As notícias enfatizavam o trabalho do cientista guatemalteco Luis von Ahn, que concebeu as captchas (Ahn et al.,2004) e as recaptchas (Ahn et al, 2008), e consta como um pioneiro da Computação Humana. O termo se refere a sistemas computacionais cada vez mais populares entre nós, que se utilizam do processamento humano para efetuar pequenas tarefas componentes de um objetivo maior (Law \& Ahn, 2011). O humano é convocado a participar em situações que a máquina não seria capaz de resolver sozinha por serem incomputáveis ou computacionalmente inviáveis. Esta situação nos remete ao pioneirismo de Alan Turing, ao conceber em 1936, o modelo formal do computador. Poucos anos mais tarde, em 1938, em sua tese de doutorado (Turing,1938), Turing vinha trabalhando numa hierarquia de sistemas formais. Partindo de um sistema (incompleto) ele descreveu um processo de "completação" de sistemas inicialmente sugerido por Gödel em seu artigo de 1931 (Godel,1965). O processo consiste em gerar um novo sistema um pouco mais completo $^{3}$ que seu precedente pela introdução de um enunciado que o fazia incompleto.

\footnotetext{
3 Aqui, os termos "completo" e "incompleto" referem-se à sistemas formais: um sistema formal é completo se a qualquer enunciado formulado no sistema corresponda uma prova de sua veracidade ou falsidade. Remetendo-se aos Teoremas da Incompletude de Gödel, Turing argumentou que embora cada
} 
Isso demandaria alguma forma de decidir a veracidade ou falsidade do enunciado em questão. Turing propôs um oráculo: alguma maneira não-maquínica que seria capaz de fornecer o passo não computável de modo a permitir o prosseguimento da tarefa de completação. Em sua tese de doutorado, Turing propôs: "algum meio não especificado de resolver problemas de teoria dos números; como se fosse uma espécie de oráculo. Não vamos mais longe na natureza deste oráculo além de dizer que ele não pode ser uma máquina" (Turing, 1938, p.18). Hoje, passados quase 80 anos, vemos a Computação Humana materializar a sugestão de Turing: o pequeno passo que ele delegou ao oráculo é o que hoje se delega ao humano. Como no caso da Computação Humana, é possível que muito do que vemos hoje na área de sistemas de informação, coisas que nos parecem essencialmente inovadoras, encontrem bases de fundamentação nos trabalhos matemáticos de um momento em que se dedicou grandes esforços criativos nos estudos relativos aos sistemas formais. Em outras palavras, fundamentos conceituais para o paradigma do século XXI denominado "computação humana" podem ser encontrados nas propostas de Alan Turing, em 1938. Assim, pode ser bastante interessante voltarmos os olhos estes estudos de modo a buscar uma melhor compreensão do nosso tempo presente.

Propomos aqui um enfoque sociotécnico que consiste em deixar aparente o percurso de construção dos conteúdos. Com isso, abrimos mão de uma concepção em que os resultados buscam explicar-se por si só, e, como bem colocou Cukierman et al., possibilitamos a verificação de que o que se diz "técnico" se conforma em coconstrução com o que se diz "social".

\section{Modos contemporâneos de compreensão e construção do conhecimento}

A questão da retenção comentada na seção 1 junta-se com a necessidade de buscar uma dinâmica em sala de aula que melhor se adapte aos modos contemporâneo de comunicação e entendimento. É possível que o recorte disciplinar em que os conteúdos estão tradicionalmente organizados já não mais dê conta de sensibilizar o estudante. As respostas aos anseios do nosso tempo não são encontradas nas disciplinas isoladas, mas no encontro entre elas, na conjunção de saberes, e por isso, o estudante está constantemente buscando, pesquisando em seus dispositivos móveis, questões relacionadas (ou não) ao que se fala em aula. Muitos dos conteúdos tradicionais já estão disponíveis em video-aulas na Internet, a qualquer tempo, em qualquer lugar e isto põe em cheque o papel do professor como enunciador de conteúdo. Os estudantes reivindicam diálogo, construções colaborativas, descentramento, e é neste espaço que o professor precisa se reposicionar para fazer circular a sua mensagem, não mais como centro catalizador, mas como parte da rede. Além disso, é preciso acompanhar o diálogo, e no fluxo dos interesses de cada turma, introduzir as questões que se quer comunicar. Por tudo isso sequência fixada de uma ementa ou programa passa a adquirir um papel orientador, apresentando questões, e não determinando o andamento das aulas.

Presenciamos hoje na sala de aula uma multiplicidade de recursos que disputam a atenção do aluno. Entretanto, o estudante parece mobilizar-se quando tem consciência

sistema de sua hierarquia fosse um pouco mais completo que o precedente, a hierarquia jamais alcançaria a completude. 
da importância de um determinado assunto na sua formação profissional. Por isso, os conteúdos programáticos precisam ser justificados. O professor que ensina precisa saber para quem e para o quê ensina, e isto invalida o modelo de "aulões", "provões" e disciplinas pré-formatadas, que colocam em primeiro plano o conteúdo e não o aluno. Invalida também a maneira como grande parte das disciplinas de conteúdo "exato" são ministradas. Uma ciência é considerada "exata" se seus conteúdos já estão de tal forma estabilizados que não admitem questionamentos. São fórmula, cálculos, que podem ser apresentados de modo a serem diretamente aplicados. Este conceito de "ciências exatas" amplifica o conflito entre um modo estático de transmissão, e a expectativa nos dias de hoje de uma construção em fluxo.

Problematizar a exatidão e rigor, ou seja, deixar aparente o processo de construção (a historicidade) dos conhecimentos quebra este conflito na medida em que coloca à vista os problemas e os embates que motivaram aquelas formulações. Destitui a imponência de um conhecimento que dispensa justificativas, abrindo possibilidades de traduções às situações inesperadas do tempo presente. Desta maneira torna-se possível ao professor situar a importância do assunto em questão à formação pretendida. No caso dos cursos de formação em computação, já foi dito, mas convém repetir que conhecer o processo de construção do computador e da computação ajuda a compreender o mundo em que vivemos hoje, onde a computação vem ocupando um espaço cada vez mais amplo, e assim verificar possibilidades futuras e conceber inovações.

\section{Teoria da Computação, uma abordagem sociotécnica.}

Durante este ano de 2016, o Curso de Sistemas de Informação da Universidade Federal Fluminense está passando por uma reforma curricular que visa, entre outros objetivos, minimizar a retenção nos primeiros períodos e adaptar os conteúdos às demandas locais. Dentre diversas mudanças elaboradas pela coordenação, em conjunto com o Núcleo Docente Estruturante, o Colegiado de Curso, e considerando as direções apontadas pelos estudantes, citamos a reorganização dos conteúdos de Matemática Discreta e Lógica Formal, em uma disciplina denominada Fundamentos Matemáticos para Computação, a ser ministrada no primeiro período do ingressante, concomitante com Teoria da Computação para Sistemas de Informação, outra disciplina recém-criada. Com base nas justificativas já comentadas nas seções anteriores, apresentamos o conteúdo programático de Teoria da Computação para Sistemas de Informação. A disciplina organiza-se em torno da linha do tempo, porém seu objetivo não é fazer um relato da sequência temporal purificada dos acontecimentos, mas trabalhar as construções matemáticas ao longo dessa diretriz. Ou seja, pretende-se uma abordagem sociotécnica, em que a matemática explica-se e explica a conjuntura em que foi concebida, e vice-versa. A elaboração desta proposta não teria sido possível sem as discussões realizadas no âmbito do Programa de Pós-Graduação em História das Ciências e das Técnicas e Epistemologia, onde as questões matemáticas são abordadas sob pontos de vistas diversos.

Objetivo: Percorrer a história do desenvolvimento matemático no decorrer do século XX, no que diz respeito às discussões sobre a fundamentação da matemática. Apresentar os conceitos fundamentais da Teoria da Computação imbricados nas situações que motivaram a sua formulação. Abordar não somente as maneiras como as construções teóricas deram suporte ao surgimento da tecnologia (computadores), mas também como as tecnologias deram suporte à 
novas construções teóricas. A partir da compreensão da construção histórica dos fundamentos da computação buscar a compreensão de situações contemporâneas envolvendo sistemas computacionais.

Embora o foco da disciplina esteja no decorrer do século XX, o curso inicia ambientando a concepção da ciência ao final do século XIX, para evidenciar como as questões emergentes no campo da matemática colocaram em cheque os anseios da ciência moderna que se queria completa e totalizante. $\mathrm{O}$ curso avança pelo século XXI para abranger questões da contemporaneidade em uma proposta de conteúdo que não pode ser completamente fixada. Embora os títulos se refiram a eventos históricos, pretende-se trabalhar em detalhe o conteúdo matemático relacionado a cada evento. Ressaltamos entre parênteses o conteúdo matemático a ser abordado, com a ressalva de que há interseções com a disciplina Fundamentos Matemáticos para Computação.

\section{Conteúdo Programático:}

Do século XIX ao século XX: As questões que intrigavam os matemáticos ao final do século XIX e os embates com a Ciência Moderna (aritmetização da análise, axiomatização da aritmética, formalização da geometria. Conjuntos indutivos e recursão primitiva a partir dos axiomas de Peano). Georg Cantor e os infinitos (coleções infinitas: enumerabilidade, cardinalidade, provas por diagonalização).

O século XX: Russell e o paradoxo (conjuntos, elementos, pertinência, conjuntos das partes). O nascimento dos programas de fundamentação da matemática: O programa Logicista, O programa Intuicionista (comparações com a lógica clássica), O programa Formalista (revisitar funções primitivas recursivas. Abordar também as parciais recursivas. Completude, Consistência, Decidibilidade de sistemas formais). O Teoremas de Gödel (numeração de Gödel, a prova da incompletude, contrapontos ao programa de Hilbert). Compreensões da matemática sob a percepção da incompletude. Propostas de formalização do conceito de computável. O cálculo lâmbda (Church/Kleene). As funções recursivas gerais (Gödel). A máquina de Turing como um programa (construção da máquina de turing). A máquina de Turing Universal (contraponto ao programa de Hilbert). Tese de Church. Evidências para a Tese de Church (equivalências entre os formalismos abordados). Compreensões filosóficas sob a percepção da incompletude. O Oráculo de Turing e a necessidade de operar com indecidíveis. A dicotomia homem-máquina e o nascimento da IA. O embate entre IA forte e IA fraca e a concepção de híbridos. Computadores, tecnologias e Segunda Guerra. Dilemas de Einstein, Russell, e Wiener. John von Neumann e a bomba atômica. John von Neumann e a implementação da máquina universal. A computação no pós-Guerra. O nascimento das $\mathrm{CC}$, as Conferências da OTAN. O não-computável e os computadores. Número Ômega (a construção do número Ômega). A situação do Brasil no cenário da computação na década de 1970. Representação computacional dos números reais. As controvérsias sobre as abordagens matematizadas e os processos sociais.

O século XXI: A teoria da computação e o suporte às novas tendências da computação: Processos colaborativos, Abordagens sociotécnicas, Computação humana.

A construção desta proposta vem ocorrendo ao longo de três períodos consecutivos em que foi oferecida como disciplina optativa. Utilizou-se como bibliografia básica, os livros textos usuais da área para cobrir o conteúdo formal com uma notação atual. Além disso, artigos da época disponíveis na internet (cartas, discursos, etc) auxiliaram não propriamente no conteúdo formal, mas para apresentar pequenos trechos onde esses autores expõem motivações e intuições das suas propostas. Trechos de filmes e documentários também contribuíram para trazer um pouco do ambiente em que se vivia a cada época. Fotografias, cartas e documentos do arquivo digital de Turing, e por fim, alguns romances (Doxiadis,2001,2010) também contribuíram para ilustrar os dilemas a época. 


\section{Referências}

Ahn, L.; Blum, M.; Langfort, J. (2004) "Telling Human and Computers apart" Em: Comm. of the ACM. Vol. 47, No. 2 , 5860. 2004.

Ahn, L.; Maurer, B.; Mcmiller, C.; Abrahn, D.; Blum, M. (2008) "reCAPTCHA: Human Based Character Recognition via Web Security Measure". Science v321.

Cafezeiro, I.; Haeusler, H.; Marques, I.; Cukierman, H. (2010) "Recontando a Computabilidade". Em: Revista Brasileira de História das Ciências, Rio de Janeiro, v. 3, n. 2, p. 231-251.

Cukierman, H.L.; Teixeira, C.; Prikladnicki, R. (2007) "Um olhar sociotécnico sobre a engenharia de software". Em: Rev. de Inf. Teórica e Aplicada, RS, UFRGS.

Curso de Qualidade (2015) "Evasão e estratégias para permanência estudantil” In: XXXV CSBC. Bento Gonçalves - RS.

Deleuze, G. \& Guatarri, F. (1997) "Mil Platôs", vol 5. São Paulo: Editora34.

Dyson, G. Turing's Cathedral: The Origins of the Digital Universe. Vintage Books.

Doxiadis, A. (2001) "Tio Petrus e a conjectura de Goldbach". São Paulo: Editora 34.

Doxiadis, A., Papadimitirus, C. (2010) Logicomix, uma jornada épica em busca da verdade. Martins Fontes.

Franzen, T., (2005) "Gödel's Theorem: An incomplete guide to its use and abuse". Wellesley, Mass.: A K Peters.

Gödel, K. (1965) On formally undecidable propositions of Principia Mathematica and related systems. Em M. Davis (Ed), The Undecidable: Basic Papers on Undecidable Propositions, Unsolvable Problems and Computable Functions. NY: Dover Pubs.

Junior, W. G. N. (2006) "O Infinito contado por Deus. Uma interpretação dedekindiana do conceito de número ordinal transfinito de Cantor". Tese Dout. Fil., PUC, RJ.

Latour, B. (2014) "Scientific Humanities, Introduction". http://www.bruno-latour.fr/courses. Law, E. Ahn, L. (2011) Human Computation. Morgan \& Claypool Publishers.

NATO $(1969,1970)$ "Software Engineering: Report of a conference sponsored by the NATO Science Committee", Scientific Affairs Division.

Setti, R. (2013) “Após digitalizar livros combatendo spams criador do duolingo quer traduzir web ensinando línguas”. O Globo, 04/06/2013

SBC (1999) "Currículo de Referência da SBC para Cursos de Graduação em Computação”. Sociedade Brasileira de Computação. Bento Gonçalves - RS.

Souza, O. S., Morais, P. S., Junior, F. C. S., (2015) "Reprovações e Trancamentos nas Disciplinas de Introdução à Programação da Universidade de São Paulo: Um Estudo Preliminar", In: XXIII WEI - XXXV CSBC. Bento Gonçalves - RS.

Turing, A. (1936) On computable numbers, with an application to the Entscheidungsproblem, Proceedings of the London Mathematical Society, Series 2, n.42, p 230-265.

Turing, A. (1938) Systems of Logic Based on Ordinals (Doctoral thesis, Princeton University). 